\title{
Evaluation of the stability of Vigabatrin in hospitalar extemporaneous formulations
}

\author{
Márcio Vinícios Ayres*a ${ }^{\mathrm{a}}$, Nathalie Ribeiro Wingert ${ }^{\mathrm{b}}$, Sarah Chagas Campanharo ${ }^{\mathrm{b}}$, Elfrides E.S.Schapoval ${ }^{\mathrm{b}}$, Martin Steppe $^{\mathrm{b}}$ \\ ${ }^{\mathrm{a}}$ Hospital de Clinicas de Porto Alegre - Pharmacy Service, Porto Alegre, Rio Grande do Sul, Brazil \\ ${ }^{b}$ Universidade Federal do Rio Grande do Sul - Graduate Program in Pharmaceutical Sciences, Porto Alegre, Rio Grande do Sul, \\ Brazil
}

*Corresponding author: martin.steppe@ufrgs.br

The aim of this study was to analyze the chemical stability of the anticonvulsant vigabatrin extemporaneous formulation from tablets in storage conditions of different temperatures and types of packaging used. The analysis of vigabatrin extemporaneous formulations were performed by high-performance liquid chromatography (HPLC). The method described in British Pharmacopoeia was co-validated for specificity, linearity, precision and accuracy. Vigabatrin extemporaneous solutions were prepared in triplicate and placed in amber glass and PET bottles, which were stored under three different conditions: at room temperature $\left(15\right.$ to $\left.30^{\circ} \mathrm{C}\right)$, under refrigeration $\left(2\right.$ to $\left.8^{\circ} \mathrm{C}\right)$, and oven $\left(40{ }^{\circ} \mathrm{C}\right)$. Samples of solutions stored at room temperature and refrigeration were collected every 7 days along 35 days. The same was done for solutions kept at $40{ }^{\circ} \mathrm{C}$, but for a period of 28 days. It was also analyzed the solutions $\mathrm{pH}$ in each sampling time. Vigabatrin extemporaneous solutions showed variations within the limits of British Pharmacopoeia 2016 up to 21 days in amber PET and glass bottles at room and refrigerated temperatures. Vigabatrin content for formulations kept in oven decreased above $10 \%$ after 7 days of study. The lowest $\mathrm{pH}$ change occurred in amber glass bottle stored under refrigeration. Results of this study will be applied as a reference for vigabatrin extemporaneous formulation in hospital, once it was demonstrated the reliability of storage time interval and proper conditions for the use. Thus, pediatric patients with fractionated doses or use of nasogastric probe will have adequately prepared extemporaneous formulations, reducing the risk of dilution errors and microbiological contamination, improving the efficacy and safety, and enabling more time for nursing assistance.

Keywords: drug stability; extemporaneous formulation; high-performance liquid chromatography; hospital; vigabatrin.

\section{Introduction}

The most commonly used drugs are in solid pharmaceutical form, however, in clinical practice, many patients require liquid dosage forms. Many medicinal products, however, are not marketed in liquid form and the pharmacist should be able to prepare this formulation from the raw material or tablets provided that the stability, formulation and preparation are well documented [1]. According to Good Manipulation Practices in Pharmacies, this transformation or extemporaneous formulation is defined as "manipulation of pharmaceutical specialty aiming at the preparation of one pharmaceutical form from another" [2]. However, changes in the pharmaceutical form may lead to changes in pharmacokinetic parameters and lead to stability problems, and in both cases therapeutic efficacy may be compromised [3].

In the hospital context, considering the numerous drugs included in drug selection, it calls attention to those who only have solid dosage forms and who do not have information about the stability of their formulation. It is these drugs that generate the need for adequate information regarding their stability and, consequently, therapeutic efficacy. The extemporaneous formulation are also widely used to administer the drugs in patients using nasoenteric probes for both fractionated and whole dose prescription drugs. A study conducted at the Hospital de Clinicas de Porto Alegre showed that $95 \%$ of patients with nasoenteric probes used solid dosage forms, mainly tablets $(72 \%)$. A total of 158 different drugs were used, and only $23 \%$ of them had a liquid pharmaceutical form [4]. The routine of prescription, preparation and administration of the leads has already been implanted and consolidated in the hospital for years and, due to the entry of new drugs in the selection of medicines, new information is required. Within this hospital context, specifically in the anticonvulsive therapy, it is possible to observe the use of several drugs in Brazil that have only presentation in the solid pharmaceutical form, such as, for example, phenytoin and vigabatrin. These drugs should be prepared as liquid formulations to suit the dose and facilitate administration to pediatric patients, however, there is no literature data regarding the stability of these drugs after formulation. Considering the use of vigabatrin in the hospital therapeutic arsenal, together with the lack of data related to the stability of the formulations and their specific use in anticonvulsant therapy, the present study aims to evaluate the behavior of this drug in solution. Thus, establishing the reliable time interval for their use with, as well as verify the most appropriate storage conditions.

Vigabatrin is chemically described as 4-amino-5-hexenoic acid. It has a molecular weight of 129.16 and its molecular formula is $\mathrm{C}_{6} \mathrm{H}_{11} \mathrm{NO}_{2} \quad$ [5,6]. It was synthesized in 1974 and was the first antiepileptic drug to be created with a mechanism of action specifically determined from the beginning of its development [7]. Vigabatrin is an amino acid analogous to gamma-aminobutyric acid (GABA). It is a racemic mixture formed by two enantiomers, but with only the active $S(+)$. It is a selective and irreversible inhibitor of GABA-transaminase, the enzyme that degrades GABA and, thereby, increases GABA levels in the central nervous system, reducing excitability $[8,9,10]$. 


\section{Methods}

\section{Samples}

Vigabatrin standard substance used had a declared content of $99.4 \%$ and the vigabatrin $500 \mathrm{mg}$ tablets used in the study were of the Sabril ${ }^{\circledR}$ brand. Each tablet contains $500 \mathrm{mg}$ of vigabatrin and the excipients are: polyvinylpyrrolidone (Povidone K30), microcrystalline cellulose, sodium starch glycolate, hydroxypropylmethylcellulose (hypromellose), magnesium stearate, titanium dioxide and polyethylene glycol 8000 (Macrogol 8000). In the covalidation of the method, a reference solution of $1.2 \mathrm{mg} / \mathrm{mL}$ vigabatrin was prepared and the vigabatrin sample solution from the tablet was also prepared in a concentration of $1.2 \mathrm{mg} / \mathrm{mL}$ (Specificity). In the stability study, the concentration of vigabatrin for solution reference and samples used was 1.0 $\mathrm{mg} / \mathrm{mL}$. The mobile phase used in the analysis was also the solvent for the formulation of these solutions.

\section{Analytical proccedures}

Analysis of vigabatrin was performed using the method described in the British Pharmacopoeia (2016). The system suitability, specificity, linearity, precision and accuracy tests were performed in order to verify the reproducibility of the pharmacopoeial method in high performance liquid chromatography (HPLC). The tests for system suitability, linearity, precision and accuracy were developed in high performance liquid chromatograph (HPLC Agilent, 1200 series model) and the specificity test was performed in other HPLC (Shimadzu, 20A model). The column used in the covalidation for separation was a cationic SCX. The mobile phase was composed of ultrapure water and potassium phosphate monobasic PA to prepare the $0.025 \mathrm{M}$ phosphate solution. This solution had the $\mathrm{pH}$ adjusted to 2.8 with orthophosphoric acid. After, methanol and acetonitrile were added to the phosphate solution. The final ratio was 1000:40:4 (v/v/v) phosphate buffer $\mathrm{pH} 2.8$, methanol and acetonitrile, respectively.

The system suitability was verified during the analysis of the linearity, observing the results in the concentration of 1.0 $\mathrm{mg} / \mathrm{mL}$, through the following parameters: retention factor $(\mathrm{k})$, repeatability (RSD), tailing factor (TF) and number of theoretical plates (N) [11]. To verify the specificity of the method, vigabatrin standard and the simulated sample of the excipients specified in the package leaflet were used. The solution of the simulated excipient sample was prepared from weighing the equivalent of the excipients contained in the mean weight of ten vigabatrin tablets, subtracting the amount of active substance. The obtained solutions were analyzed for their chromatographic profile to verify possible interferences of the excipients at the peak related to vigabatrin. The linearity of the method was evaluated by constructing a standard curve containing six different concentrations for three consecutive days. Solution reference of vigabatrin 1.2 $\mathrm{mg} / \mathrm{mL}$ was diluted to obtain concentrations of $0.2 \mathrm{mg} / \mathrm{mL}$; $0.4 \mathrm{mg} / \mathrm{mL} ; 0.6 \mathrm{mg} / \mathrm{mL} ; 0.8 \mathrm{mg} / \mathrm{mL}$ and $1.0 \mathrm{mg} / \mathrm{mL}$, respectively. For each concentration, readings were performed in triplicate. The standard curve was constructed using a concentration versus absolute area graph. The equation of the line was determined from the linear regression by least squares method. Precision was determined by the inter-repeatability, intermediate precision and by the calculation of the relative standard deviation (RSD) obtained from the analyzes performed during the determination of linearity on three consecutive days. Accuracy was determined using solution reference of vigabatrin at the concentration of $1.2 \mathrm{mg} / \mathrm{mL}$ and vigabatrin sample at a concentration of $1.2 \mathrm{mg} / \mathrm{mL}$. For the recovery test, three reference solutions were prepared, obtaining the concentrations $0.75 \mathrm{mg} / \mathrm{mL}, 0.90 \mathrm{mg} / \mathrm{mL}$ and $1.20 \mathrm{mg} / \mathrm{mL}$, respectively.

\section{Stability Study of Vigabatrin extemporaneous formulations}

Samples for the stability study were prepared in a vertical laminar flow chamber. Eighteen flasks with a capacity of 100 $\mathrm{ml}$ were used to prepare the samples, nine amber glass and nine polyethylene terephthalate (PET) bottles. In each of the eighteen flasks were added a $500 \mathrm{mg}$ vigabatrin tablet and $100 \mathrm{~mL}$ water for injection with syringe aid, sealed with cap and shaken for dissolution of the tablets, resulting in the concentration of $5 \mathrm{mg} / \mathrm{mL}$. After they were separated and labeled by stability study group, as follows:

- three amber glass bottles for stability study in refrigerated temperature $\left(2\right.$ to $\left.8^{\circ} \mathrm{C}\right)$;

- three bottles of amber PET for stability study in refrigerated temperature $\left(2\right.$ to $\left.8^{\circ} \mathrm{C}\right)$;

- three amber glass bottles for stability study at room temperature $\left(15\right.$ to $\left.30{ }^{\circ} \mathrm{C}\right)$;

- three bottles of amber PET for stability study at room temperature $\left(15\right.$ to $\left.30{ }^{\circ} \mathrm{C}\right)$;

- three amber glass bottles for stability study in temperature at $40{ }^{\circ} \mathrm{C}$;

- three bottles of amber PET for stability study in temperature at $40{ }^{\circ} \mathrm{C}$.

The refrigerator and room temperatures were monitored and recorded daily. The microbiological oven was fixed at $40{ }^{\circ} \mathrm{C}$ for the stability study. Samples were collected every 7 days for a period of 35 days for the stability study of glass and amber PET bottles at refrigerated and ambient temperature. Samples stored in oven were collected every 7 days for a period of 28 days for the stability study of the glass bottles and amber PET in an oven at a temperature of $40{ }^{\circ} \mathrm{C}$. Two $\mathrm{mL}$ of each sample vial $(5.0 \mathrm{mg} / \mathrm{mL})$ were collected with the aid of an automatic pipet and added in a 10 $\mathrm{mL}$ volumetric flask. The volume was completed with mobile phase, resulting in the final concentration of $1.0 \mathrm{mg} / \mathrm{mL}$. All collected samples were analyzed by HPLC at each collection time, together with standard reference vigabatrin prepared at the concentration of $1.0 \mathrm{mg} / \mathrm{mL}$. The $\mathrm{pH}$ check was performed every 7 days on the vigabatrin samples prepared and left under the same conditions. The procedure was carried out for the period of 35 days for the samples stored in refrigerated and ambient temperature and, for 28 days, for samples stored in an oven. 


\section{Results and Discussion}

\section{Evaluation of the analysis method}

Table 1 shows the results of the system suitability parameters obtained by the chromatographic method during covalidation (linearity) at the concentration of $1.0 \mathrm{mg} / \mathrm{mL}$ vigabatrin. The specificity of the chromatographic method was evaluated by comparing the chromatograms obtained (vigabatrin standard, excipient mixture and vigabatrin extemporaneous formulation) in order to verify the possible interference of the excipients in the determination of vigabatrin. It was observed that there is no interference of the adjuvants components of the tablet, because they had less retention time than vigabatrin. Figure 1 shows the chromatogram of vigabatrin standard substance and figures 2 and 3 show the chromatograms of the simulated excipient sample and the vigabatrin extemporaneous formulation, respectively.

Table 1. System suitability parameters recommended for HPLC in covalidation and those obtained experimentally for vigabatrin analysis $^{11}$.

\begin{tabular}{ccc}
\hline Parameters & Proposed & Values found \\
\hline Retention factor (k) & $\mathrm{k}>2$ & 10.48 \\
Repeatability (RSD) & $\mathrm{RSD}<1 \%$ & 0.43 \\
Resolution (Rs) & $\mathrm{Rs}>2$ & $29.04^{\mathrm{a}}$ \\
Tailing factor (TF) & $\mathrm{TF} \leq 2$ & 1.14 \\
Nuber of plates (N) & $>2000$ (HPLC) & 5930 \\
\hline
\end{tabular}

${ }^{\mathrm{a}}$ In relation to the solvent peak.

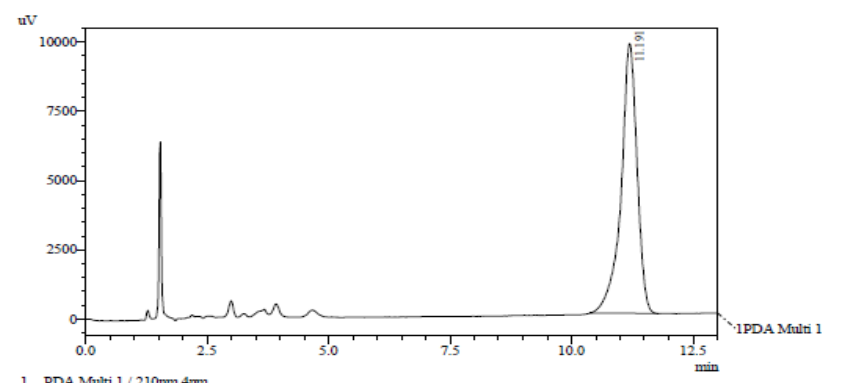

Figure 1. Chromatogram of vigabatrin standard substance at the 1.0 $\mathrm{mg} / \mathrm{mL}$ concentration obtained by HPLC in the Shimadzu apparatus, model $20 \mathrm{~A}$.

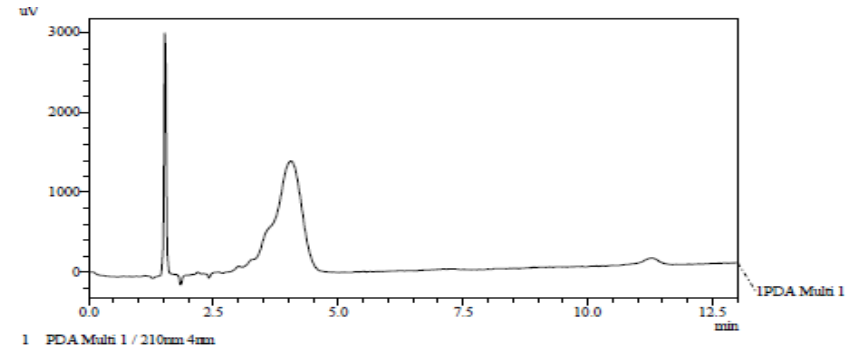

Figure 2. Chromatogram of the simulated excipient sample obtained by HPLC in the Shimadzu, model 20A equipment.

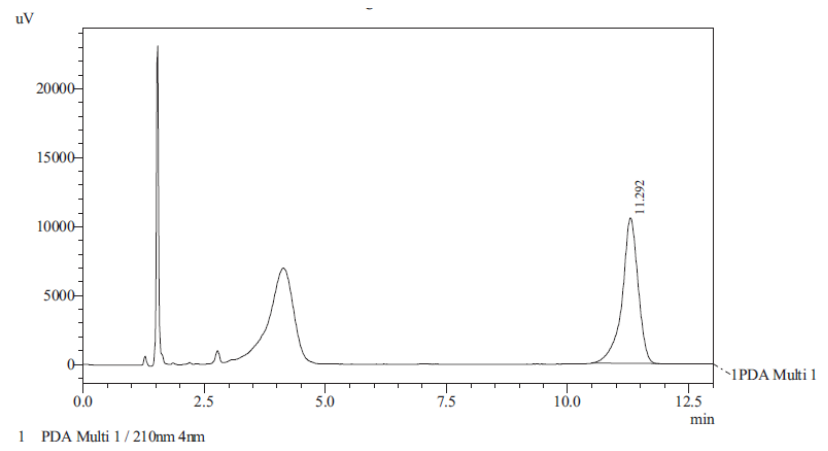

Figure 3. Chromatogram of vigabatrin tablet preparation at 1.0 $\mathrm{mg} / \mathrm{mL}$ concentration obtained by HPLC in the Shimadzu apparatus, model $20 \mathrm{~A}$.

Table 2 shows the experimental values of absolute areas of vigabatrin, referring to the concentration range used for vigabatrin by HPLC. The graphical representation of the standard curve of vigabatrin standard substance, obtained by the HPLC technique, is shown in figure 4.

Table 2. Absolute areas of vigabatrin standard substance obtained by HPLC to determine the standard curve.

\begin{tabular}{ccc}
$\begin{array}{c}\text { Concentration } \\
(\mathbf{m g} / \mathbf{m L})\end{array}$ & Area $^{\mathrm{b}}$ & RSD \\
\hline 0.2 & 52.00 & 1.899 \\
0.4 & 106.70 & 2.085 \\
0.6 & 154.20 & 1.327 \\
0.8 & 208.50 & 0.655 \\
1.0 & 263.80 & 1.013 \\
1.2 & 313.90 & 1.008
\end{tabular}

${ }^{b}$ Each value represents the average of the triplicates of the determinations carried out in three days. 


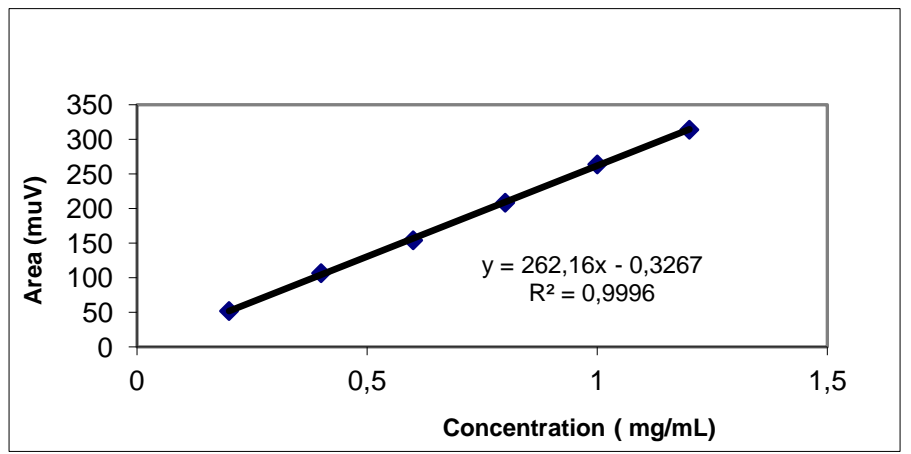

Figure 4. Graphical representation of the standard curve of vigabatrin standard substance obtained by HPLC.

The experimental values obtained in the determination of vigabatrin standard substance by HPLC are described in table 3 , from the determination of the repeatability and intermediate accuracy performed in triplicate for three consecutive days. The experimental values for the accuracy calculated through the recovery test are shown in table 4.

Table 3. Experimental values obtained in the determination of accuracy from vigabatrin standard substance.

\begin{tabular}{ccccc}
\hline $\begin{array}{c}\text { Concentration } \\
(\mathbf{m g} / \mathbf{m L})\end{array}$ & Day & Area $^{\mathrm{c}}$ & $\begin{array}{c}\text { RSD } \\
\text { (intraday) }\end{array}$ & $\begin{array}{c}\text { RSD } \\
\text { (interday) }\end{array}$ \\
\hline 0.2 & 1 & 52.60 & 0.66 & \\
& 2 & 52.17 & 1.82 & 2.04 \\
& 3 & 51.20 & 3.04 & \\
\hline 0.8 & 1 & 209.97 & 0.60 & \\
& 2 & 207.53 & 0.34 & 0.65 \\
& 3 & 207.97 & 0.26 & \\
\hline 1.2 & 1 & 313.13 & 0.35 & 1.01 \\
& 2 & 310.87 & 0.28 & \\
& 3 & 317.83 & 0.13 &
\end{tabular}

${ }^{c}$ Each value represents the average of the triplicates of the determinations carried out in three days.

Table 4. Experimental values obtained in the determination of recovery accuracy from vigabatrin tablets.

\begin{tabular}{cccc}
$\begin{array}{c}\text { Sample } \\
\text { concentration } \\
(\mathbf{m g} / \mathbf{m L})\end{array}$ & $\begin{array}{c}\text { Concentration } \\
\text { found } \\
(\mathbf{m g} / \mathbf{m L})^{\mathbf{d}}\end{array}$ & $\begin{array}{c}\text { Recovery } \\
(\boldsymbol{\%})\end{array}$ & RSD \\
\hline 0.75 & 0.71 & 94.22 & 0.82 \\
0.90 & 0.87 & 96.30 & 0.67 \\
1.20 & 1.17 & 97.22 & 0.49 \\
\hline
\end{tabular}

${ }^{\mathrm{d}}$ The value represents the average of three determinations.

\section{Stability of Vigabatrin extemporaneous formulations}

Table 5 shows the experimental values obtained by HPLC of the vigabatrin extemporaneous formulations, prepared at the concentration of $1.0 \mathrm{mg} / \mathrm{mL}$ and packed in amber glass bottles and amber PET bottles, stored under refrigeration (2 to $8{ }^{\circ} \mathrm{C}$ ) and evaluated for a period of 35 days. Figure 5 shows the values of the vigabatrin concentration versus time, stored in an amber glass bottle and under refrigeration. Figure 6 shows the values of vigabatrin concentration versus time, stored in an amber PET bottle and under refrigeration. Table 6 shows the experimental values obtained by HPLC of the vigabatrin extemporaneous formulations, prepared at the concentration of $1.0 \mathrm{mg} / \mathrm{mL}$ and packed in amber glass bottles and amber PET bottles, stored at room temperature $\left(15\right.$ to $30{ }^{\circ} \mathrm{C}$ ) and evaluated for a period of 35 days. Figure 7 shows the vigabatrin concentration versus time stored in an amber glass bottle at room temperature. Figure 8 shows the concentration of vigabatrin versus time stored in an amber PET bottle at room temperature. Table 7 shows the experimental values obtained by HPLC of the vigabatrin extemporaneous formulations, prepared at the concentration of $1.0 \mathrm{mg} / \mathrm{mL}$ and conditioned in amber glass bottles and amber PET bottles, stored at a temperature of $40{ }^{\circ} \mathrm{C}$ and evaluated for a period of 28 days. Figures 9 and 10 represent vigabatrin concentration versus time values stored in amber glass bottle and amber PET bottle, respectively, at $40{ }^{\circ} \mathrm{C}$. The $\mathrm{pH}$ values for the measurements performed at each time are described in table 8 . The graphical representation of $\mathrm{pH}$ values is shown in figure 11 .

Table 5. Results of mean concentrations of vigabatrin stored in amber glass bottles and amber PET bottles under refrigeration ( 2 to $\left.8{ }^{\circ} \mathrm{C}\right)$ analyzed by HPLC at the specified times.

\begin{tabular}{ccccc}
\hline \multicolumn{5}{c}{ Mean concentration $(\mathbf{m g} / \mathbf{m L})$} \\
\hline $\begin{array}{c}\text { Time } \\
\text { (days) }\end{array}$ & $\begin{array}{c}\text { Glass } \\
\text { bottle }^{\mathrm{e}}\end{array}$ & RSD & $\begin{array}{c}\text { PET } \\
\text { bottle }^{\mathrm{e}}\end{array}$ & RSD \\
\hline $\mathbf{0}$ & 1.0092 & 0.06 & 1.0092 & 0.06 \\
$\mathbf{7}$ & 1.0129 & 0.64 & 1.0177 & 0.79 \\
$\mathbf{1 4}$ & 0.9925 & 0.60 & 1.0126 & 0.72 \\
$\mathbf{2 1}$ & 1.0022 & 0.44 & 0.9885 & 0.39 \\
$\mathbf{2 8}$ & 0.8918 & 0.82 & 0.8987 & 0.45 \\
$\mathbf{3 5}$ & 0.8754 & 0.14 & 0.8734 & 0.18
\end{tabular}

${ }^{\mathrm{e}}$ Each value represents the mean of the triplicates of the determinations. 


\section{GLASS BOTTLE - REFRIGERATION}

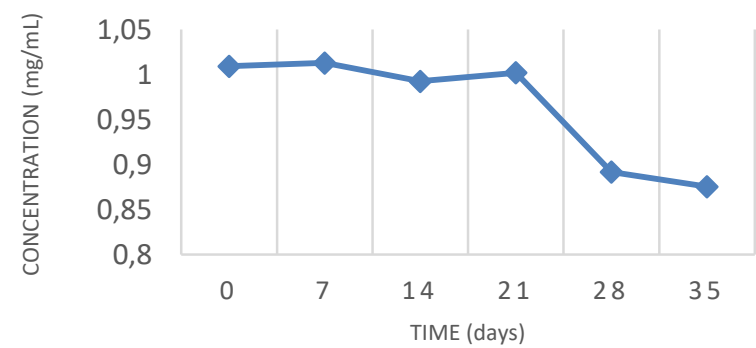

Figure 5. Graphical representation of the concentration of vigabatrin stored in an amber glass bottle under refrigerated temperature versus time.

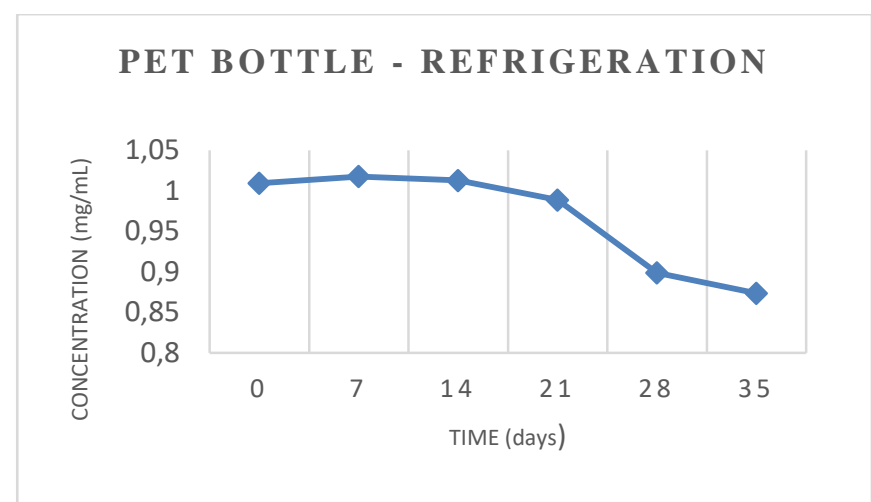

Figure 6. Graphical representation of the concentration of vigabatrin stored in an amber PET bottle under refrigerated temperature versus time.

Table 6. Results of mean vigabatrin concentrations stored in amber glass bottles and amber PET bottles at room temperature (15 to $30^{\circ}$ C), analyzed by HPLC at the specified times.

\section{Mean concentration $(\mathrm{mg} / \mathrm{mL})$}

\begin{tabular}{ccccc}
\hline $\begin{array}{c}\text { Time } \\
\text { (days) }\end{array}$ & $\begin{array}{c}\text { Glass bottle } \\
\mathrm{f}\end{array}$ & RSD & $\begin{array}{c}\text { PET bottle } \\
\mathrm{f}\end{array}$ & RSD \\
\hline $\mathbf{0}$ & 1.0092 & 0.06 & 1.009 & 0.06 \\
$\mathbf{7}$ & 1.0202 & 0.23 & 1.0083 & 0.21 \\
$\mathbf{1 4}$ & 1.0251 & 0.63 & 1.0206 & 1.74 \\
$\mathbf{2 1}$ & 0.9953 & 0.72 & 0.9815 & 0.42 \\
$\mathbf{2 8}$ & 0.9101 & 0.70 & 0.9027 & 0.42 \\
$\mathbf{3 5}$ & 0.8862 & 0.37 & 0.8822 & 0.10 \\
\hline
\end{tabular}

${ }^{\mathrm{f}}$ Each value represents the mean of the triplicates of the determinations.

\section{GLASS BOTTLE - ROOM TEMPERATURE}

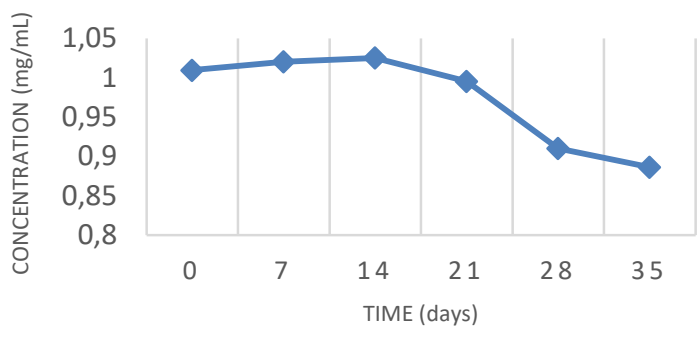

Figure 7. Graphical representation of the concentration of vigabatrin stored in an amber glass bottles at room temperature versus time.

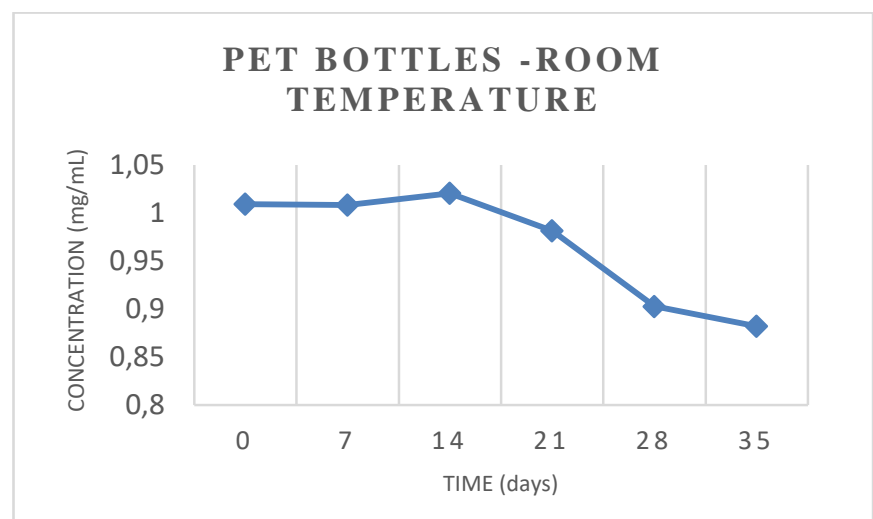

Figure 8. Graphical representation of the concentration of vigabatrin stored in an amber PET bottle at room temperature versus time.

Table 7. Results of mean concentrations of vigabatrin stored in amber glass bottles and amber PET bottles in an oven $\left(40^{\circ} \mathrm{C}\right)$ analyzed by HPLC at the specified times.

\section{Mean concentration $(\mathbf{m g} / \mathbf{m L})$}

\begin{tabular}{lllll}
\hline $\begin{array}{l}\text { Time } \\
\text { days) }\end{array}$ & Glass bottle $^{\mathrm{g}}$ & RSD & PET bottle $^{\mathrm{g}}$ & RSD \\
\hline $\mathbf{0}$ & 1.0092 & 0.06 & 1.0092 & 0.06 \\
$\mathbf{7}$ & 0.8889 & 0.15 & 0.8828 & 0.15 \\
$\mathbf{1 4}$ & 0.8797 & 0.10 & 0.9123 & 0.44 \\
$\mathbf{2 1}$ & 0.8848 & 0.08 & 0.8960 & 0.15 \\
$\mathbf{2 8}$ & 0.8822 & 0.04 & 0.8906 & 0.19 \\
\hline
\end{tabular}

${ }^{\mathrm{g}}$ Each value represents the mean of the triplicates of the determinations. 


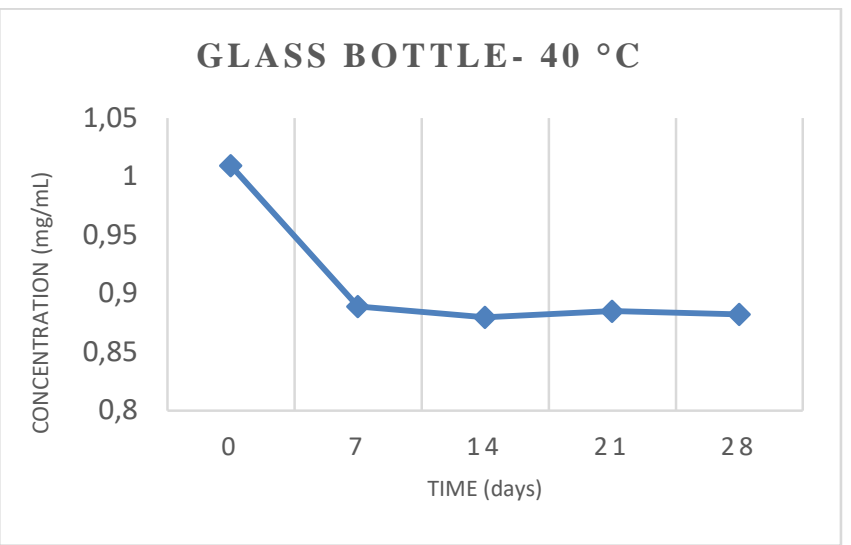

Figure 9. Graphical representation of the concentration of vigabatrin stored in an amber glass bottle at $40^{\circ} \mathrm{C}$ versus time.

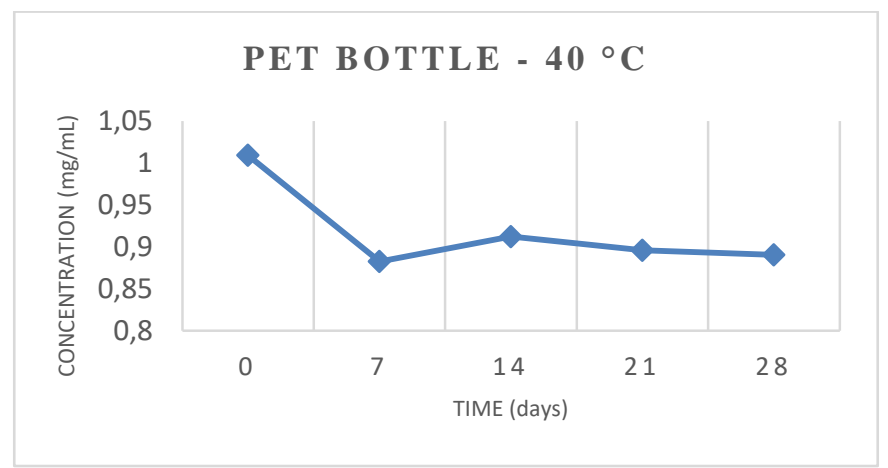

Figure 10. Graphical representation of the concentration of vigabatrin stored in an amber PET bottle at $40^{\circ} \mathrm{C}$ versus time.

Table 8. $\mathrm{pH}$ values found in the vigabatrin extemporaneous formulation, depending on the type of packaging material and the mode of storage. Table legend: TA (room temperature); TR (refrigerated temperature); T40 (oven temperature); G (glass bottle); P (PET bottle).

\begin{tabular}{|c|c|c|c|c|c|c|}
\hline Time (days) & \multirow[b]{2}{*}{ 0 } & \multirow[b]{2}{*}{7} & \multirow[b]{2}{*}{14} & \multirow[b]{2}{*}{21} & \multirow[b]{2}{*}{28} & \multirow[b]{2}{*}{35} \\
\hline $\begin{array}{c}\text { Temperature/ } \\
\text { Material }\end{array}$ & & & & & & \\
\hline TA/P & 6.97 & 6.28 & 6.22 & 6.21 & 6.15 & 5.73 \\
\hline TA/G & 7.13 & 6.47 & 6.33 & 6.26 & 6.24 & 5.64 \\
\hline TR/P & 6.94 & 6.93 & 7.16 & 7.08 & 6.97 & 6.55 \\
\hline TR/G & 7.25 & 7.14 & 7.06 & 7.24 & 7.07 & 7.21 \\
\hline T40/P & 6.89 & 6.49 & 6.27 & 6.20 & 6.18 & 5.68 \\
\hline T40/G & 6.89 & 6.62 & 6.33 & 6.24 & 6.24 & 5.65 \\
\hline
\end{tabular}

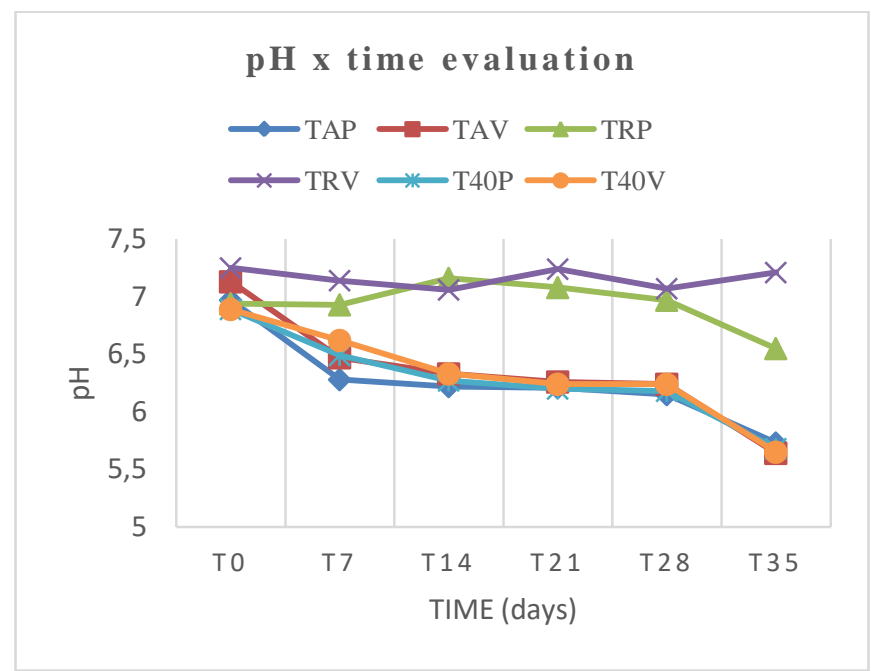

Figure 11. Graphical representation of the $\mathrm{pH}$ of VIGABATRIN stored in glass vial and amber PET under refrigerated temperature, ambient and oven at $40^{\circ} \mathrm{C}$ versus time. Graph legend: TA (room temperature); TR (refrigerated temperature); $\mathrm{T} 40$ (oven temperature); V (glass bottle); P (PET bottle).

\section{Evaluation of the analysis method by HPLC}

Suitability of the system

Before developing the validation analyzes, it should be established that the HPLC system and procedures are capable of yielding data of acceptable quality. These tests are used to verify that system resolution and repeatability are adequate. The suitability of the system is the control of a system to ensure adequate performance before or during the analysis [11]. According to the results indicated in table 1, the suitability parameters evaluated are in accordance with the pertinent literature and qualify the method of vigabatrin analysis.

\section{Specificity}

Specificity or selectivity is the ability to unequivocally evaluate the substances under consideration in the presence of components that may interfere with their determination in a complex sample [12]. The specificity of the method was evaluated by comparing the chromatograms obtained (standard substance and excipients), allowing to evaluate the interference of the excipients. The analysis of the chromatograms of Figures 1,2 and 3 indicates that there is no interference of the excipients with the vigabatrin signal. The chromatographic peak around 4 minutes refers to the excipient polyvinylpyrrolidone (PVP), as previously cited by CHEN [13]. Therefore, the proposed method has adequate specificity. 


\section{Linearity}

Linearity corresponds to the ability of the method to provide results directly proportional to the concentration of the test substance within a given application range [12]. Figures 5 and 6 present the vigabatrin chromatograms at concentrations of $0.2 \mathrm{mg} / \mathrm{mL}$ and $1.2 \mathrm{mg} / \mathrm{mL}$, respectively, representing the lowest and highest concentration of the curve in the linearity graph. This range of concentrations was used by CHEN to verify the linearity at the wavelength of the study $(210 \mathrm{~nm})$ [13]. According to figures 4, 5 and 6 it can be observed that proportionality occurred between the range of concentrations and their respective peak areas. In previous covalidation analysis, concentrations below $0.2 \mathrm{mg} / \mathrm{mL}$ were found to be poorly detected. This is due to the lack of a chromophore group in the vigabatrin molecule, which makes it difficult to detect by spectrophotometric absorption [14]. The linearity of the method presented coefficient of correlation (r) equal to 0.9999 , therefore, satisfactory to the criteria established by RE 899 of ANVISA [15].

\section{Precision}

Precision represents the dispersion of results between independent, repeated assays of the same sample, similar sample or patterns, under defined conditions [12]. Three points of the linearity curve were evaluated. The lowest concentration $(0.2 \mathrm{mg} / \mathrm{mL})$, the mean concentration $(0.8$ $\mathrm{mg} / \mathrm{mL})$ and the highest concentration $(1.2 \mathrm{mg} / \mathrm{mL})$, according to table 2 . Repeatability (intraday) and intermediate (interday) showed a RSD of less than $5 \%$. Therefore, the result is satisfactory and meets the criteria of RE 899, demonstrating adequate repeatability and reproducibility [15].

\section{Accuracy}

Accuracy represents the degree of agreement between the individual results found in a given trial and a reference value accepted as true [12]. According to the analysis performed by CHEN, the mean recovery obtained was $99.8 \%$ with RSD of $1.4 \%$ [13]. According to Table 3, the accuracy showed a mean recovery percentage of $95.9 \%$ and mean RSD of $0.66 \%$. These results indicate that the method has adequate accuracy.

\section{Stability of Vigabatrin extemporaneous formulations}

Many variables influence the chemical stability of drugs. Specifically in this study, the influence of temperature and the type of packaging material were evaluated. The concentration of the vigabatrin sample at time zero was $1.0092 \mathrm{mg} / \mathrm{mL}$ and RSD was $0.06 \%$, indicating that the initial concentration of vigabatrin was in agreement with the concentration of standard substance. In the evaluation of vigabatrin shunts in glass bottles and amber PET bottles at refrigerated temperature (Figures 7 and 8), it is possible to observe that the $1.0 \mathrm{mg} / \mathrm{mL}$ concentration of vigabatrin was reduced until the maximum study time of 35 days. There was a percentage reduction of the vigabatrin concentration of $13.26 \%$ and $13.46 \%$ in amber glass bottles and amber PET bottles, respectively, from time zero to the time of 35 days. The percentage difference in the reduction of the vigabatrin concentration between the types of packaging material of the bottles was only $0.20 \%$. At refrigerated temperature, (figures 7 and 8), it is verified that up to the time of 21 days there was a percentage decrease in the concentration of vigabatrin of only $0.69 \%$ and of $2.05 \%$ in the bottles of amber glass and PET, respectively. When the 28-day time is observed, a more abrupt reduction occurs for both vials, with a drop of $11.63 \%$ and $10.95 \%$ in amber glass bottles and amber PET bottles, respectively, comparing them with the concentration of vigabatrin at time zero. In the evaluation of the shunts of vigabatrin in amber glass bottle and amber PET bottle at room temperature (figures 7 and 8), there was a percentage reduction of the vigabatrin concentration of $12.19 \%$ and of $12.58 \%$ in amber glass bottles and amber PET bottle, respectively, from time zero to the time of 35 days. The percentage difference of the reduction between the types of packaging material of the bottles was $0.39 \%$. At room temperature, observing figures 9 and 10, it was observed that up to the time of 21 days there was a percentage decrease in the concentration of vigabatrin of only $1.38 \%$ and of $2.74 \%$ in amber glass bottles and amber PET bottles, respectively. When the 28-day time was observed, as in the refrigerated temperature, a more abrupt reduction occurred for both flasks, dropping $9.82 \%$ and $10.55 \%$ in amber glass bottles and amber PET bottles, respectively, comparing them with the vigabatrin concentration at time zero, at room temperature. According to the British Pharmacopoeia, the variation in the concentration of vigabatrin allowed in tablets is $\pm 5 \%$.

Considering this parameter and evaluating the results, it was observed that these values do not represent a significant decrease of the initial content, demonstrating vigabatrin stability up to the 21 days time for the refrigerated and ambient temperature conditions, as well as for the type of material of packaging (amber glass and PET) [16]. In the evaluation of the shunts of vigabatrin in a glass bottle and amber PET bottle in an oven at $40^{\circ} \mathrm{C}$ (Figures 11 and 12), there was a more pronounced percentage reduction of the vigabatrin concentration from the time of 7 days. The decrease in vigabatrin concentration was $11.92 \%$ and $12.52 \%$ in amber glass bottles and amber PET bottle, respectively, from time zero to time of 7 days. The percent reduction from time zero to the time of 28 days was $12.58 \%$ and $11.75 \%$ in amber glass bottles and amber PET bottles, respectively, indicating that the concentration of vigabatrin after the reduction observed in the time of 7 days, remained practically constant. Temperature is one of the primary factors affecting drug stability [17]. The choice of temperatures to perform the stability study was to verify if the study drug was stable at the most usual temperatures to store the medicines (refrigerated and environment), and to verify if the higher temperature would influence the stability of vigabatrin. In addition to temperature, the second most important variable in drug degradation is $\mathrm{pH}$. The effect of $\mathrm{pH}$ on the degradation of drugs in aqueous solutions has been well studied. It can be explained by the catalytic action that the $\mathrm{H}^{+}$and $\mathrm{OH}^{-}$ions can exert on various chemical reactions [17]. The evaluation of the $\mathrm{pH}$ of the vigabatrin leads (Figure 13) showed that, at room temperature, there was a $17.79 \%$ reduction in the amber PET bottle and a $20.90 \%$ reduction in the amber glass bottle. In refrigerated temperature, a lower $\mathrm{pH}$ variation occurred, where a reduction of $5.62 \%$ was 
observed in amber PET bottles and only $0.55 \%$ in amber glass bottles. The $\mathrm{pH}$ reduction with the greatest variation between zero time and 35 days occurred at room temperature and in both types of packaging materials. At the temperature of $40^{\circ} \mathrm{C}$ it was observed that in both types of packaging concomitant reduction of $\mathrm{pH}$ occurred. In the amber glass bottle there was a reduction of $\mathrm{pH}$ in $18 \%$ of time zero until the time of 35 days. In the amber PET bottle, $\mathrm{pH}$ reduction occurred at $17.56 \%$ of time zero until the time 35 days. Therefore, there is only $0.44 \%$ difference between the types of packaging material. Lowering the $\mathrm{pH}$ may suggest an early drug degradation process, although the production degradation products, as well as significant reduction of the drug content, have not occurred.

At all temperatures analyzed, no chromatographic peaks were formed related to a possible degradation process at the collection times. According to CHEN, the primary degradation product of vigabatrin is 5-ethenyl-2-pyrrolidone and in analysis by HPLC, the retention time of the chromatographic peak of this product is about 5 minutes [13]. Packaging plays an important role in maintaining quality and it is crucial that stability tests of the dosage forms in the final package are carried out. The role of packaging is to protect the pharmaceutical form of light, moisture and oxygen, as well as exposure to other types of factors that may influence the quality of the final product. However, pharmaceutical products may interact with the packaging material and the concentration of the active substances may be reduced by adsorption, absorption or incorporation by the packaging material [17]. The results regarding the types of packaging material showed a variation of less than $1 \%$ in all temperatures studied, suggesting that there was no significant difference between the glass and PET packages. This study did not aim to conduct chemical kinetics studies of the degradation of vigabatrin. Due to the limited literature on the stability of vigabatrin, the results could already predict whether or not the factors studied could interfere with the stability of the derivation of this drug.

\section{Applicability of Vigabatrin extemporaneous formulations for hospital use}

Extemporaneous formulations for hospital use require stability data to ensure efficacy and safety of the drug for a short period of use. Due to the variability in dosage and dosage of prescriptions of patients, especially pediatric patients, in addition to frequent changes of these, the leads are prepared for a few days. In addition, as recommended in RDC 67/2007 of ANVISA, formulation are considered to be extemporaneous formulations and should be prepared for only 48 hours if chemical stability is proven [2]. In a hospital environment, in order to guarantee patient safety, this short term refers to the microbiological stability of the formulation. Observing the results of this chemical stability study, vigabatrin could be incorporated into the routine for the formulation of the Hospital de Clinicas formulation, in response to a long-standing demand from the care team regarding the difficulty in preparing and administering this drug to the patient. Broadening the view of the topic, it is important to emphasize that due to the entry of new drugs into the therapeutic arsenal, further stability studies will be needed. It is not only studies of chemical stability of the drug derived from a tablet or capsule, but of possible interactions with other drugs, with the patient's diet, chemical compatibility when administered by nasoenteric tube among other variables found in the hospital environment, showing how much is relationship. Therefore, it is important for the pharmacist to be attentive to the needs of the patient, most of times identified through the nursing team that provides direct assistance, preparing and administering the latter's medications. More importantly, in addition to identifying these needs, the pharmacist seeks solutions that impact on improved care, focusing on patient safety. Such needs are not only characteristics of Brazil, but a global problem. Following the advent of thalidomide, the pharmaceutical industry has launched several licensed adult medications on the market, stating that more studies in children will be needed or that it has not been evaluated for such use. This situation considers pediatric patients as "therapeutic orphans", making the prescription of doses, from a newborn patient to the adolescent patient, difficult for the physician to determine, often extrapolating the adult dose [18, 19]. There is a worldwide critique of pharmaceutical laboratories, regarding the lack of presentations of medicines directed to pediatric patients, as well as adequate information regarding dose and dosage, considering the differentiated physiology during each stage of the child's development. Thus, there is not generation of scientific information that meets the requirements and promotes authorization of medicines for use in the pediatric population through regulatory agencies $[18,20]$. A study by CUZZOLIN has shown that, despite changes in regulatory agencies in the United States and in the European Community, creating policies and stimulating pharmacological research in pediatrics, few studies have been directed at newborns. However, there was an increase in the registration of medicines directed to pediatrics, reducing the need for medicines derived or manipulated, but still, insufficient [19].

According to the World Health Organization (WHO), essential medicines as those for pediatric use should be a priority in research. However, these drugs continue to be used without this information [20]. Vigabatrin is a real example of this problem. In Brazil, only the tablet presentation is recorded. The powder is not registered for the extemporaneous formulation of the oral solution, as it is in Europe, where it is specifically used to facilitate the administration of the prescribed dose and improve the palatability of the medicine, thus ensuring greater safety for the pediatric patient. At the national level, issues related to the marketing interest of pharmaceutical companies, or even the lack of specific demands of regulatory bodies, still lack appropriate answers. Another important aspect that arises is the variability of modes of formulation of a drug when it is necessary to prepare it. Due to the lack of information in the literature on stability, formulations, compatibility among others, there is no standard formulation with these aspects taken care of. In addition, the use of excipients that have a toxic effect on newborns corroborates this concern [20]. A prospective study of 117 master pharmacies (commercial and institutional) showed that the formulation of caffeine citrate solution $20 \mathrm{mg} / \mathrm{mL}$ used formulations with different excipients, demonstrating the concern of WHO cited above [21]. Therefore, the stability study of vigabatrin contemplated only the use of water for the formulation of the leads. In the 
routine of Hospital de Clinicas, the leads are prepared with water for injections only without the use of other excipients, since the leads are prepared as extemporaneous formulations. In rare exceptions, when there is a need for masking of flavor, contact of the nurse or clinical pharmacist requests the extemporaneous formulation with simple syrup or syrup with flavoring. In these cases, it is verified in the stability study of the drug in question, if there is information of incompatibility. Several drugs do not be mixed with syrup because sucrose promotes chemical interaction. It is the case of the Maillard reaction that occurs between reducing sugars and the primary amino group of amino acids, for example [17]. Another important aspect is the formulation of referrals that pose a risk to the personnel involved, such as cytotoxic drugs. Care with individual protection and specific area, appropriate for the formulation, are necessary to guarantee the safety of those involved in the process [18]. The RDC $67 / 2007$ of ANVISA is the legislation that specifies the necessary conditions for each group of medicines, where Annex VI regulates on the manipulation of formulation in the master pharmacy [2]. Therefore, despite the efforts of regulatory agencies in other countries to stimulate studies involving the use of medicines in the pediatric population, there is still little in relation to needs. In Brazil, there is still a lack of many presentations of medicines that attend to this public, leading necessarily to extemporaneous formulations of tablets and capsules, in order to meet the therapeutic needs of pediatrics. Therefore, the search for information regarding stability studies of pediatric formulations is unavoidable and efforts in this regard are still needed.

\section{Conclusions}

The vigabatrin did not show reduction of content higher than specified in the British Pharmacopoeia 2016, up to the time of 21 days, at room temperature and refrigerated. The variation of vigabatrin content between the type of packaging (glass and PET) in the time of 21 days is less than $1 \%$, at room temperature and refrigerated; The results obtained may serve as a subsidy for extemporaneous pediatric formulations of vigabatrin in the hospital routine, guaranteeing greater safety in the formulation and efficacy in the treatment of epileptic syndromes.

\section{Conflict of interest}

The authors declare that there are no financial or nonfinancial conflicts of interests in the development of this research work. This research did not receive any specific grant from funding agencies in the public, commercial, or not-for-profit sectors.

\section{References}

1. Souza GB. Manipulação magistral de medicamentos em pediatria. 2nd ed. São Paulo: Pharmabooks, 2003:5-7.

2. Agência Nacional de Vigilância Sanitária. Resolução da Diretoria Colegiada nr. 67. Brasília, DF; 2007 Oct. Diário Oficial da República Federativa do Brasil.
3. Gomes MJ, Reis AM. Ciências farmacêuticas: uma abordagem em farmácia hospitalar. 1st ed. São Paulo: Atheneu, 2011:387-405.

4. Heydrich J, Heineck I, Bueno D. Observation of formulation and administration of drugs by nursing assistants in patients with enteral feeding tube. Brazilian Journal of Pharmaceutical Sciences. 2009; 45:1-4.

5. Chemblink. Online database of chemicals from around the world. http://www.chemblink.com/products/68506-86-5.htm. Accessed 2014 Jun 30

6. Drugbank. Drug and drug target database. Version 5.0. http://www.drugbank.ca/drugs/DB01080. Accessed 2016 Apr 30.

7. Yacubian EMT, Caicedo GC, Pohl LR (Ed.). Tratamiento farmacológico de las epilepsias. São Paulo: Leitura Médica. 2014:143-147.

8. Rogers SJ, Cavazos JE. Epilepsy. In: Dipiro JT et al. Pharmacotherapy: a pathophysiologic approach. New York: McGraw Hill; 2014:855-877.

9. Patsalos PN. Drug Interactions with the newer antiepileptic drugs (AEDs) - part 1: pharmacokinetic and pharmodynamic interactions between AEDs. Clin Pharmacokinet. 2013; 52:927-966.

10. UPTODATE. Evidence-based clinical decision support at the point of view. www.uptodate.com/contents/antiseizuredrugs-mechanisms-of-action-pharmacology-adverse-efects.

Accessed 2016 Jun 01.

11. Shabir GA. Validation of high performance liquid chromatography methods of pharmaceutical analysis. Understanding the differences and similarities between validation requirements of the US Food and Drug Administration, the United States of Pharmacopeia and the International Conference on Harmonization. J Chromatogr A. 2003; 987:57-66.

12. Ribani M. Validação em métodos cromatográficos e eletroforéticos. Quim Nova. 2004; 27:771-780.

13. Chen, TM, Contario, JJ, Fike, RR. High-performance liquid chromatographic assay for vigabatrin and its primary degradation product in a pharmaceutical tablet formulation. $J$ chromatogr. 1987; 398:351-354.

14. Wu HL, Lin FM, Kou HS, et al. Capillary electrophoresis analysis of gabapentin and vigabarin in pharmaceutical formulations as ofloxacin derivatives. Anal Chim Acta. 2004; 523:9-14.

15. Agência Nacional de Vigilância Sanitária. Resolução da Diretoria colegiada RE n. 899. Brasília, DF; 2003 Jun. Diário Oficial da República Federativa do Brasil.

16. British pharmacopoeia 2016. London: The Stationery Office; 2016:3504.

17. Yoshioka S, Stella, V. Stability of drugs and dosage forms. New York: Kluwer Academic Publishers; 2002:61-96. 
18. Conroy S. Extemporaneous (magistral) formulation of oral medicines for children in European hospitals. Acta Paediatr. 2003; 92:408-410.

19. Cuzzolin L. Off-label drug in the newborn. Journal of Pediatric and Neonatal Individualized Medicine. 2014; 3:1-8.

20. World health organization. Essential medicines and health products.

http://www.who.int/medicines/publications/essentialmedicine s/en/. Accessed 2016 Oct 10.

21. Tradeway, AK, Craddock D, Leff R. Practices of pharmacies that compound extemporaneous formulations. Am J Health-Syst Pharm. 2007; 64:1403-1409. 